4th International Scientific Conference SEC-IASR 2019, Galati, Romania, 7th - 8th June, 2019

\title{
Recovery Following a Posterior Hemivertebrectomy through Swimming and Schroth Therapy
}

\author{
Florin TURCANU, Simona Pia FAGARAS, Dana Simona \\ TURCANU, Alexandru PACURARU, Laura Edith CIULEA \\ https://doi.org/10.18662/lumproc/sec-iasr2019/35
}

How to cite: Turcanu, F., Fagaras, S.P., Turcanu, D.S., Pacuraru, A., Ciulea, L.E. (2020). Recovery Following a Posterior Hemivertebrectomy through Swimming and Schroth Therapy. In S. Marin \& P. Moisescu (vol. eds.), Lumen Proceedings: Vol. 12. 4th International Scientific Conference SEC-IASR 2019 (pp. 327-334). Iasi, Romania: LUMEN Publishing House. https://doi.org/10.18662/lumproc/sec-iasr2019/35 



\title{
Recovery Following a Posterior Hemivertebrectomy through Swimming and Schroth Therapy
}

\author{
Florin TURCANU ${ }^{1}$, Simona Pia FAGARAS ${ }^{*}$, Dana Simona \\ TURCANU $^{3}$, Alexandru PACURARU ${ }^{4}$, Laura Edith CIULEA ${ }^{5}$
}

Abstract

This present study was run during 21.06.2018 - 20.02.2019 and aims to present a program for the recovery of cifoscolysis caused by the presence of a thoracic hemivertebre, remuoved by surgery at PONDERAS Academic Hospital from Bucharest.The imaging performed before the surgery (Rx, CT, MRI) show the following: the left T10 hemivertebra is completely segmented by a posterior quadrant, with a secondary Cobb T9-T11=46 degrees scoliosis, T12-L4=50 degrees; right vertebral pedicle T9 type D; no medullary or posterior pit anomalies. The pacient aged 14, performs the regular medical check-up at Recover Bucharest, and the actual recovery by using the Schroth technique at OrtoprofilTirguMures, and through swimming at Aqua per Salus within the University of Medicine, Pharmacy, Sciences and Technology from TirguMures. During this present study, we used the method of observation through the interpretation of the full spine MRI performed every 3 months following the first period of 6 weeks when the first post-surgery control was performed. At the 20th week of surgery, there was a correction of scoliosis T12-L4 by 4 degrees to scoliosis before surgery. Through Schrothtehnic specific exercises and Brass and Backe swimming, in the next 28 weeks a T8-T12 junctionacifosis was corected 5 degrees from previous examination.

Keywords: Hemivertebra; Schroth Technique; Scoliosis; Kiphosis; Swimming.

\footnotetext{
1 University of Medicine, Pharmacy, Science and Technology, TirguMures, Romania, florinboby69@yahoo.com

2 University of Medicine, Pharmacy, Science and Technology, TirguMures, Romania, monihaba@yahoo.com

3 University of Medicine, Pharmacy, Science and Technology, TirguMures, Romania, dane68mona@yahoo.com

4 The Stat University of Physical Education and Sport, Chisinau, Rep. Moldova, pacuraru2002ro@yahoo.com

5 University of Medicine, Pharmacy, Science and Technology, TirguMures, Romania, caffenoname@,yahoo.com
} 


\section{Introduction}

The Schroth therapy represents a three-dimensional therapeutic approach of the scoliosis which was conceived by Katharina Schroth at the beginning of the 1900s. Through creativity, methodical thinking and a great deal of effort, Schroth tried to repair her scoliosis by placing a great emphasis on respiration and muscular contraction.

The purpose of this Therapy is is based on the active elongation of the column, on the derotation of the vertebras through three-dimensional respiration, as well as on the toning and stretching of the muscles in a maximum corrective position.

The exercises aim for the correction of the scoliotic posture and try to attain a normal bodily image. Before starting the therapy, a very important and absolutely mandatory aspect is the evaluation of the patient and the establishment the type of scoliotic curve according to the Schroth classification. At the same time, scoliosis can be highlighted or even worsened through the presence of a hemivertebra.

\section{Problem Statement}

Scoliosis can occur as a result of advanced degenerative changes which may be asymmetric, causing the vertebrae to rotate and lose their alignment with each other [1].

Nowadays the practice of swimming can ensure the nerve motor and musculoskeletal rehabilitation and can prevent physical deficiencies of the spine. Also the practice of swimming harmonizes the body of global and segmental viewpoint and help to balance the body weight [3].

A retrospective study of 26 patients with congenital scoliosis due to hemivertebra was conducted. Curve progression was analysed regarding the type of hemivertebra, its localization, and the applied treatment. The worst results were found in girls, in cases who were diagnosed with more than to years of age, in thoraco-lumbar curves, in multiple hemivertebra, especially in non-adjacent segmented unilateral hemivertebra and, finally, in patients treated with orthopaedic methods [2].

\section{Research Questions/Aims of the research}

The purpose of this present research is to present (this theme will be disseminated in several parts, the first part being represented by the program of recovery from the first 18 weeks following the surgical intervention) a 
kinetic program of recovery (week 20-48), following a posterior hemivertebrectomy on a patient of 14 years old by using the Schroth Therapy and swimming - Craul technique.

We can formulate the general hypothesis of the study in the following manner: we assume that by means of a specialized recovery program following a Ruf-Harms hemivertebrectomy in the first 18 weeks, based on physical exercises and Schroth therapy and continued through the same therapy completed with breaststroke swimming we can register superior indices regarding the right lumbar scoliosis and the thorax-lumbar junctional kyphosis.

\section{Research Methods}

In this particular case, the hemivertebra was found around the age of 12 years old, even though in the year of 2013, when the patient was 8 years old, a radiography of the spine was wrongly interpreted! A subsequent evaluation (made in 2017), by performing a Rx, CT, MRI and by consulting some specialists from 4 specialty clinics in France, Hungary, Austria and Switzerland led to a precise diagnosis: the left T10 hemivertebra is completely segmented by a posterior quadrant, with a secondary Cobb T9T11=46 degrees scoliosis, T12-L4=50 degrees; right vertebral pedicle T9 type D; no medullary or posterior pit anomalies (figure 1):

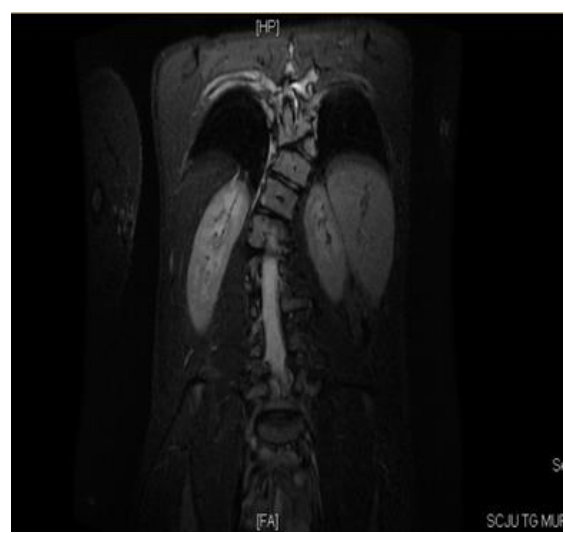

Figure 1 Hemivertebra T10

Within this present study we have used the method of observation via the interpretation of the full spine MRI performed on 20.02.2019, when the specialty examination was performed at Recover Clinic in Bucharest by 
Dr. Al. Th., the specialist who also performed the surgical intervention at Ponderas Academic Hospital in Bucharest.

This present study was performed during 21.06.2018 - 20.02.2019. The actual recovery by using the Schroth technique has taken place at Ortoprofil Tîrgu Mureş, and through swimming at Aqua per Salus within the University of Medicine, Pharmacy, Sciences and Technology in Tîrgu Mures.

The subject of this present study is T,.D.A., of 14 years.

The program meant to correct scoliosis consisted of exercises at the margin of the pool in deep water:

1. Mixed hanging with the back oriented towards the pool's stairs, with the left hand seizing higher than the body, the body is extended while breathing in and returns to the initial position while breathing out;

2. Hanging with the left hand toward the margin, breaking the wave, while the right arm is positioned at $90^{\circ}$ on the water surface, the patient performs swing movements of his feet in a frontal plane $\mathrm{x} 10$;

3. From the same initial position, the right leg will be extended and bowed x10.

The post-surgery recovery program recommended by Dr. A.T. together with the physical therapist Sz.J., aim at aligning the spine by activating mainly the paravertebral, abdominal, thoracic muscles performing chest or concentric abdominal breathing (figure 2-7)

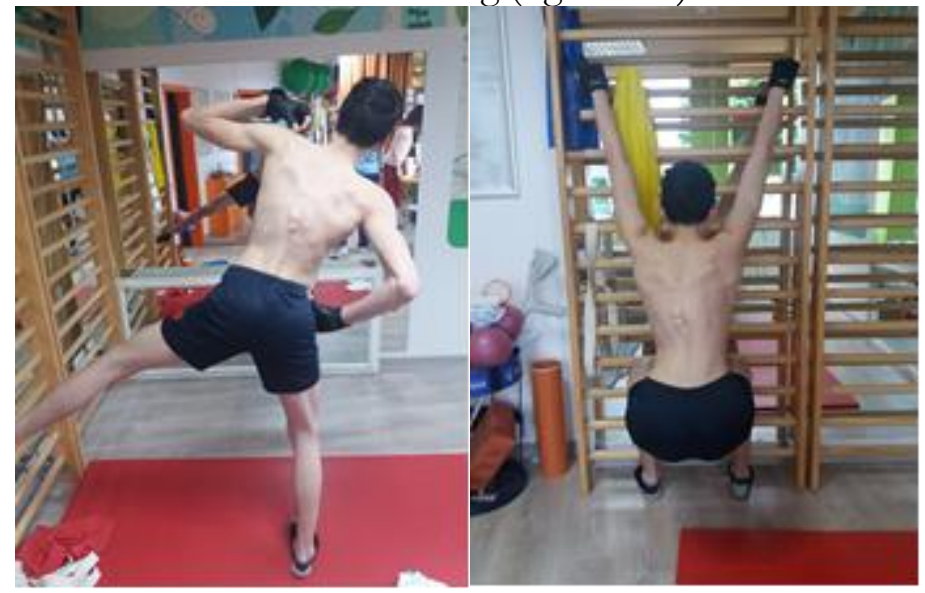

Figure 2
Figure 3 


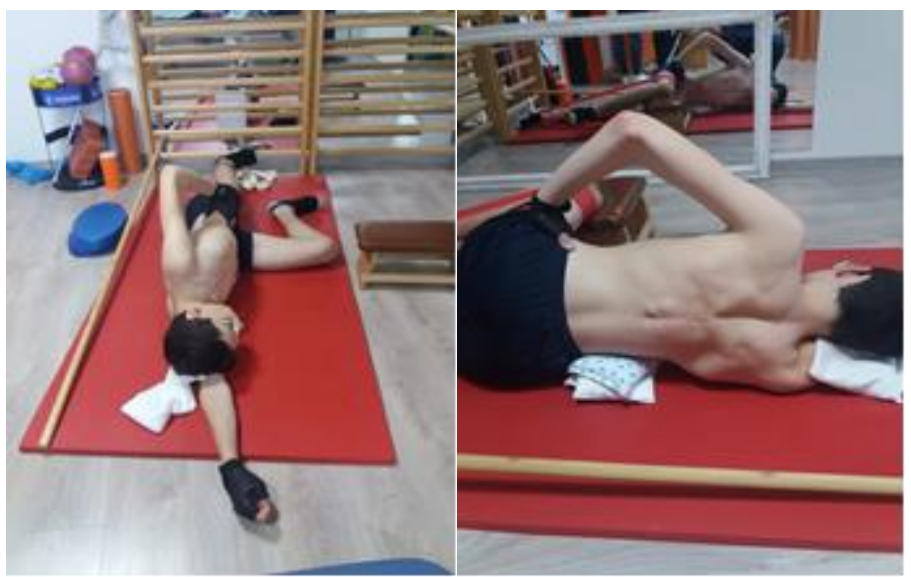

Figure 4

Figure 5

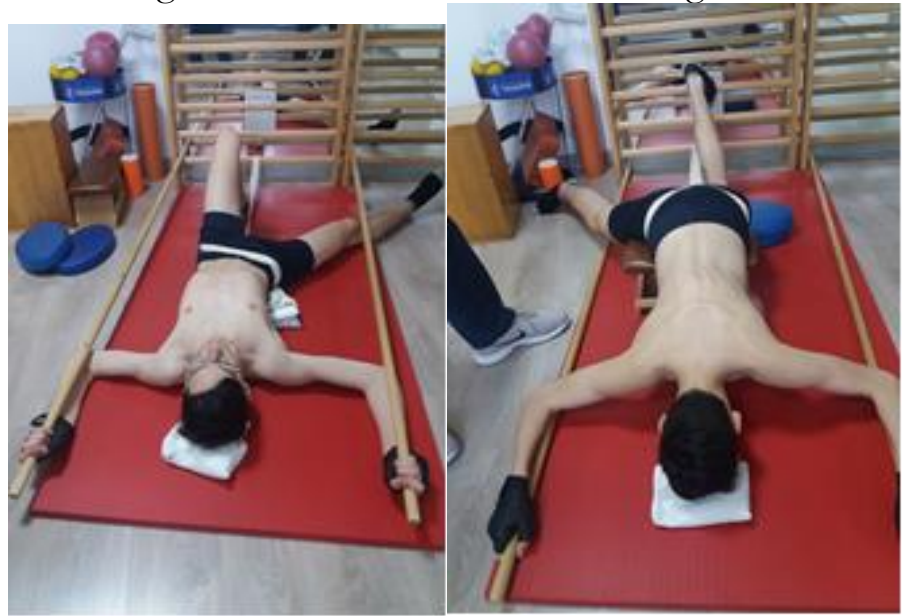

Figure 6

Figure 7

\section{Findings}

Within the paper, I have used the following tests:

- The test of evaluation of the lateral mobility;

- The test of rotation of the vertebral spine.

The testing of the muscular force at the level of the muscles of the vertebral spine is forbidden according to the indications of the physician who performed the surgical intervention.

The values of the T12-L4 scoliosis and of the T8-T12 kyphosis on 20.02.2019, measured by performing a Rx are shown in table no. 1: 
Florin TURCANU \& ... | Lumen Proceedings 12 | SEC-IASR 2019

Table 1. The values of the scoliosis and the kyphosis

\begin{tabular}{lll}
\hline The date of registration & Scoliosis & Kyphosis \\
\hline At 20 weeks & $41^{\circ}$ & $39^{\circ}$ \\
At 48 weeks & $41^{\circ}$ & $34^{\circ}$ \\
\hline
\end{tabular}

\section{Discussions}

From the analysis of table no. 1 one can notice the fact that for the scoliosis, the values remained unchanged. The kyphosis registered values smaller with 5 degrees in comparison with the registration performed after 20 weeks from the surgical intervention. This interpretation is exemplified through figure no. 8 where, on the 1st position, the values of the scoliosis can be found, and on the 2nd position the values of the kyphosis can be found:

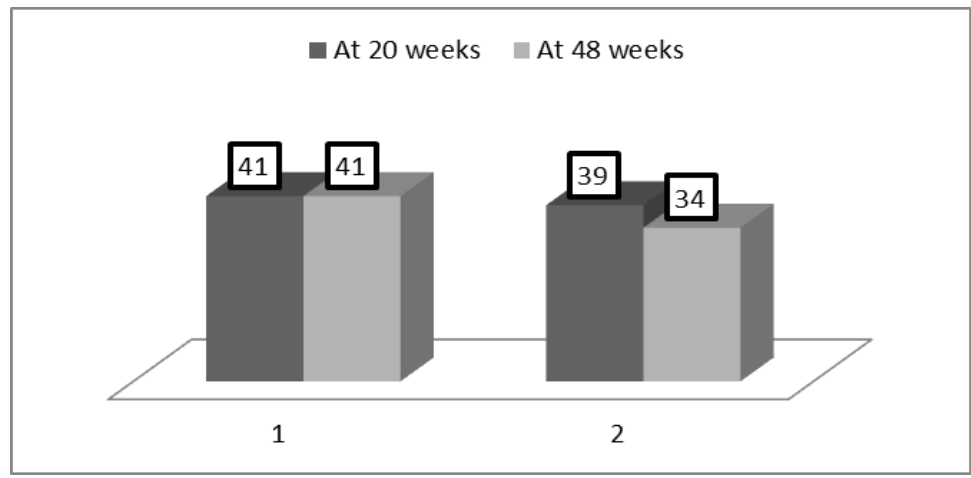

Figure 8 The indices of the scoliosis and of the kyphosis

Given all these measurements, we can affirm that the results registered at 48 weeks since the hemivertebrectomy are partly positive, with hopes of a progressive correction for both the scoliosis and the kyphosis.

This statement is based also on the following 2 images where one can notice postural attitude (right) and the 8 points recovered remaining (left - Pedi-Scoliometer) (figures 9, 10): 


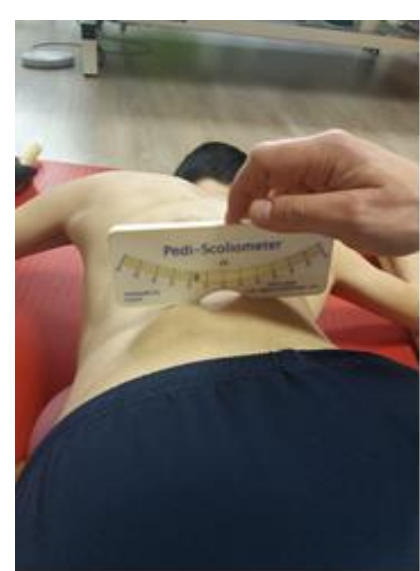

Figure 9

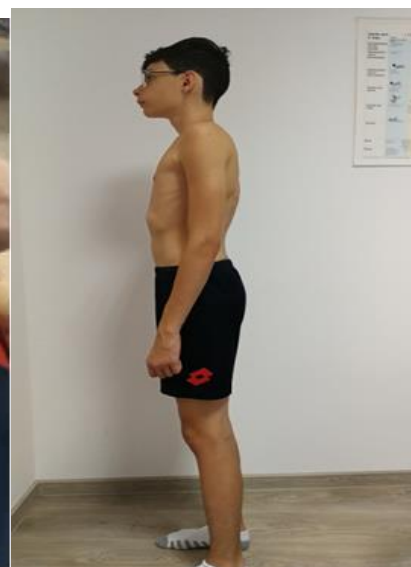

Figure 10

Pedi-ScoliometerPostural attitude

The hypothesis of this present study is confirmed in the respect that by applying some exercises through Schroth therapy a correction of the kyphosis with 5 degrees and the maintaining of the scoliosis at 41 degrees and, therefore, its lack of aggravation, were achieved.

The result obtained following the final examination of the lateral mobility of the vertebral spine is positive. If we analyse Figure 11, we can depict an increase of the lateral mobility of the right side (1) with $0,5 \mathrm{~cm}$. and another positive result of $1,5 \mathrm{~cm}$. on the left side (2).

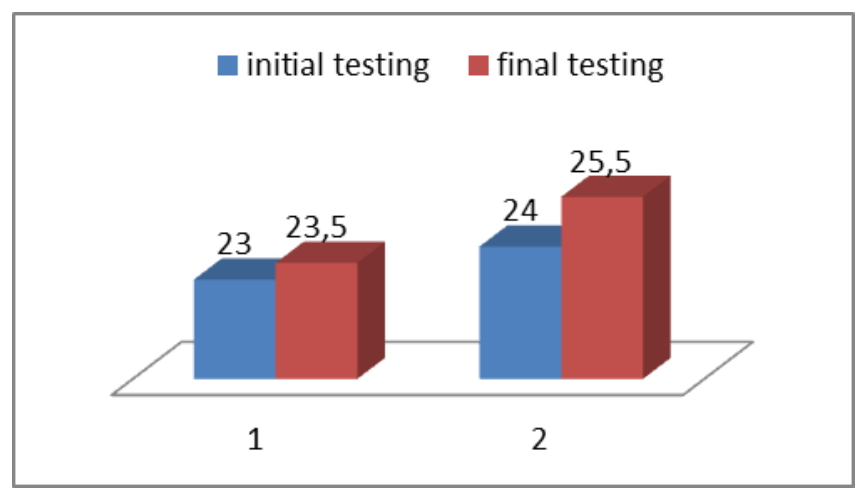

Figure 11 Lateral mobility Test

The results obtained following the final examination at the rotation test of the vertebral spine registered an increase of the torsion capacity with $2^{\circ}$ on the right side and approximate $1^{\circ}$ on the left side, following the measurements performed with the goniometer (Figure 12): 


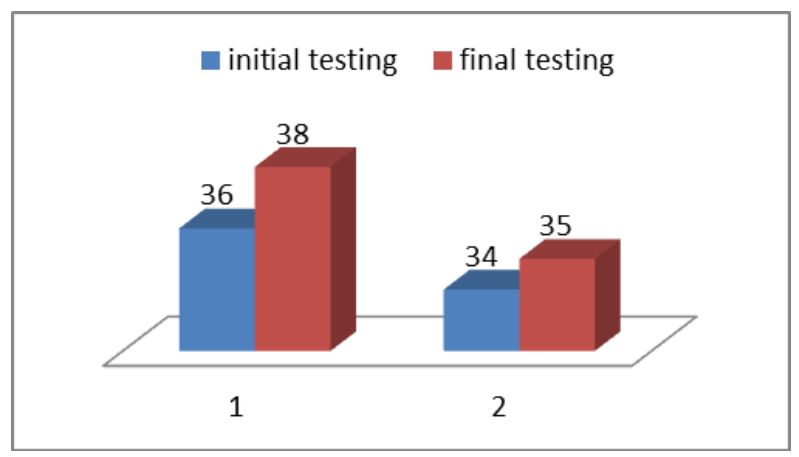

Figure 12 Rotation Test

\section{Conclusions}

Due to the complexity of the case, taking into account in this respect the surgical intervention, the multitude of recovery technics of the Schroth therapy adapted to the subject of this present study, but mostly to the mental preparation implied by the entire recovery program which will be prolonged at least until the patient is 18-19 years old, we can state some preliminary conclusions, which in time can generate certain final conclusions which would converge towards the fulfilment of the general goal - the recovery of both the scoliosis and kyphosis caused by a hemivertebra, respectively, by applying Schroth therapy.

The kinetic exercises using the Schroth therapy must be adapted according to the typology of the scoliosis, according to the apparition or lack of apparition of the kyphosis, according to the rotation of the column and especially according to the existence or lack of existence of a hemivertebra. The exercises presented in the study represent a guiding mark, a possible model but which must be mandatorily adapted according to the function and morpho-functional particularities of the patient.

\section{References}

[1] Scott DH, William HKW, Thomas NB Jr. The Encyclopedia of Visual Medicine Series - An Atlas of Back Pain. The Parthenon Publishing Group. 2002. pp. 55, 59.

[2] Villanueva Garcia E, Perez Belmonte C. Revista espanola de cirugia osteoarticular. 31(186):293-298.

Rață S. Prevenirea şi corectatea deficienței fizice scolioza prin înot terapeutic. Ştiința culturii fizice, USEFS; 2014, 17 (1): 76-82. Available from: https://ibn.idsi.md/sites/default/files/imag file/Prevenirea $\% 20$ si $\% 20$ corectar ea $\% 20$ deficientei $\% 20$ fizice $\% 20$ scolioza $\% 20$ prin $\% 20 \%$ C $3 \%$ AEnot $\% 20$ terapeuti c.pdf. 